\title{
A 3R Implementation Framework to Enable Circular Consumption in Community
}

\author{
Q. Z. Yang, Jifeng Zhou, and Kaihua Xu
}

\begin{abstract}
Circular consumption is an indispensible part of a circular economic system for sustaining the economic growth and mitigating environmental degradation and resource depletion. How to put circular consumption into practice is however a challenge. This paper presents the development of an implementation framework, based on the reduce-reuse-recycle (3R) principle of the Circular Economy theory, for enabling circular consumption in community and for accelerating the pro-3R lifestyle change at the household level. The framework consists of a set of 3R functions to support residents' practicing circular consumption, a carbon labeling and carbon credit scheme, a partnership program with producers and distributors, and mechanisms to shape pro-3R habits and sustainable lifestyles in community. The framework has been implemented in twenty 3R-enabled community shops in Wuhan and Jingmen cities in China. They demonstrate a novel type of functions that retailing shops can perform in encouraging $3 R$ activities to achieve the goals of circular consumption.
\end{abstract}

Index Terms-3R principle, behavioral change, circular consumption, circular economy.

\section{INTRODUCTION}

With its huge population, rapid urbanization, and growing economy, China is having a significant impact on global consumption. However, the current linear consumption patterns in China, that is, the "take-make-dispose" model [1] have generated enormous pressures with the degradation of the environment, depletion of exploitable resources, and emissions of waste and pollutants far beyond its borders. These challenging issues call for a large-scale transition from the conventional linear system to a circular form of consumption. Among other enabling mechanisms to bring the concept of circular consumption (CC) to life, the reduce-reuse-recycle (3R) approaches are commonly recognized as an effective $\mathrm{CC}$ implementation measure. $3 \mathrm{R}$ will be the focus of this study.

This paper reviews the development of a $3 R$ implementation framework for circular consumption in community and for accelerating the pro-3R lifestyle change at the household level. The framework is built with 3R functions to enable the residents' circular consumption practices, and with mechanisms to encourage consumption behavioral change and sustainable lifestyle in community. It also provides a carbon labeling and carbon credit scheme to disclose the carbon information of household goods in

Manuscript received on August 15, 2013; revised September 29, 2013.

Q. Z. Yang is with the Circular Economy Research Center and GEM High-Tech Co. Ltd, 430074 China (e-mail: yangqizhengem@163.com).

Zhou Jifeng and Xu Kaihua are with the GEM High-Tech Co. Ltd, 518101 Shenzhen, China. support of residents' purchase decisions and in reward of their low-carbon activities. In addition, a partnership program with producers and distributors is included in the framework to align production and supply of circular solutions for alternative consumption choices. Basic functions of the framework are $3 \mathrm{R}$ services. Implemented in 3R-enabled community retailing networks, these 3R-based commercial services include:

- Retailing of low-carbon and environment-protective products for reducing household energy and water consumptions at the product use stage and minimizing household waste discharge;

- Consignment and exchange of second-hand goods for reusing the used products over multiple product life cycles; and

- Collection and trading of discarded household appliances and other end-of-life products for recycling the regenerative waste.

Besides these 3R services with retail shops for residents to practice circular consumption, the framework also supports the consumption behavior change and pro-3R lifestyles by awareness rising, public information and community education. The details of the framework and its implementation in community retailing shops are elaborated in Section III.

\section{BACKGROUND AND CONCEPTS}

\section{A. Population, Urbanization and Economic Growth in China}

China has about 1.35 billion people in 2012. The current urban population is $52.6 \%$ of the total according to the official statistics [2]. Its urbanization rate will continuously increase to $60 \%$ by 2020 and $80 \%$ by the middle of this century [3]. From now to 2020, about 300 million people will be moving from rural to urban areas in China. Far from their rural roots and ancestral connection with nature, urbanized consumers consume vast amounts of products completely divorced from any basic needs [4].

Urban lifestyles have had strong influences on China's consumption patterns and its economy. On the one hand, urbanization as a critical driver will further stimulate the economic development. China's economy has grown at an average rate of $10.6 \%$ per year since 2005 [2]. If the economy was now to grow at $7.5 \% \sim 8 \%$ per year, the GDP per capita in 2030 for China's projected population of 1.45 billion would rise from the current $\$ 6,091$ [2] to around $\$ 38,000$, making China the world's largest economy then. On the other hand, rapid urbanization would result in huge resource demands and severe environmental pressures, if we continue the 
TABLE I: MAJOR INDICATORS FOR WATER AND AIR POLLUTION CONTROL IN THE 12TH FYP (2010 2015)

\begin{tabular}{|c|c|c|c|c|}
\hline Indicators & Unit & 2010 & 2015 & Growth by 2015 over 2010 \\
\hline Chemical Oxygen Demand (COD) & 10,000 tons & 2551.7 & 2347.6 & $-8 \%$ \\
\hline Ammonia Nitrogen & 10,000 tons & 264.4 & 238.0 & $-10 \%$ \\
\hline Sulphur Dioxide (SO2) & 10,000 tons & 2267.8 & 2086.4 & $-8 \%$ \\
\hline Nitrogen Oxides (NOx) & 10,000 tons & 2273.6 & 2046.2 & $-10 \%$ \\
\hline Proportion of Grade-V surface water in state-controlled sections & $\%$ & 17.7 & $<15$ & -2.7 percentage points \\
\hline $\begin{array}{l}\text { Proportion of Grade-I and II water in state-controlled sections of the } \\
\text { seven major river systems }\end{array}$ & $\%$ & 55 & $>60$ & 5 percentage points \\
\hline $\begin{array}{l}\text { Proportion of cities at the prefecture level or above with Grade-II or } \\
\text { better air quality }\end{array}$ & $\%$ & 72 & $\geq 80$ & 8 percentage points \\
\hline
\end{tabular}

\section{B. Resource and Environmental Issues}

Resource depletion in our planet has been ongoing at a rate that cannot be sustained. According to a recent study by Staniškis, human consumption is $30 \%$ larger than nature's capacity to regenerate and resource demand on the planet has nearly tripled over the past 50 years [5]. Another report from IGES analyzed that if the emerging middle class in Asia decides to consume like the average American, then we will need four to five additional planets [4] to support our growing resource needs. In China, the relationship between resource/environment and high-speed economic development has been a long-time concern. China's economic growth model has suffered from the problems of high resource utilization, high energy intensity, high emissions, low recycling and low efficiency [6]. To improve the situation, the 12th Five-Year Plan (FYP) for National Environmental Protection in China has set a series of mandatory targets [7] for environmental protection and resources conservation. Table I lists seven indicators for environmental quality to control water and air pollutions.

The resource conservation targets for energy consumption, water use, forest stock and others are also identified as shown in Table II.

TABLE II: SOME RESOURCE CONSERVATION GOALS DURING THE 12TH FYP (2010 2015) IN CHINA

"By 2015, the energy consumption per unit GDP will be reduced by $16 \%$, the carbon intensity by $17 \%$, and the water consumption per unit industrial added value by $30 \%$. The non-fossil energy share of total primary energy consumption will reach $11.4 \%$, and the forest stock will increase by 600 million cubic meters."

-Zhang Ping, NDRC Chairman, in speech to the UN Rio+20 Symposium, Beiiing. 8 September. 2011

To achieve the environmental quality and the resource conservation targets above, our existing linear economic development mode has to be changed, such as to a circular economy.

\section{Circular Economy, 3R and Circular Consumption}

In China, a circular economy (CE) has been positioned as one of the key concepts under its overall national development plans: both the 11th (2005-2010) and 12th (2010-2015) FYPs. A framework law to promote CE was enacted in 2008. In the law, the concept of circular economy is defined as a generic term for all the activities of reducing, reusing and recycling (3R) during the production, circulation, consumption and other processes [8]. The core principle of the circular economy in China is "3R":

- Reducing the consumption of resources and the generation of wastes/pollutants in the process of production, circulation and consumption;

- Reusing the discards as products directly or after repair, refurbishment or remanufacturing, or reusing them, wholly or partly, as parts of other products; and

- Recycling waste as raw materials for direct use or regenerative use after waste recovery.

The CE concept and its 3R principle promote a transition of the economic growth mode from a linear model of resource-product-waste to a circular model of resourceproduct-waste-(reused or regenerated) resource. Fig. 1 shows features of the linear and circular models. The fundamental difference is to close the resource loop with the circular model.

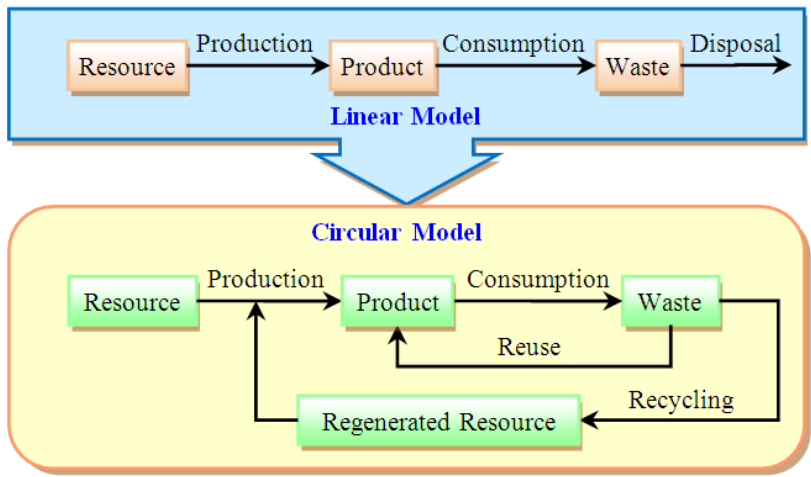

Fig. 1. Features of the linear and circular models.

The purpose of CE is to improve the resource utilization efficiency and protect the environment for sustainable development. The 3R-based $\mathrm{CE}$ approach describes a sustainable economic growth mode for China to decouple the economic development from the increased use of resources (such as materials, energy, water, land, forest, etc.) and from the profound ecological and environmental damages. To facilitate the transition towards CE, China has set a series of policies and targets. For example, in the first national CE Strategy and Action Plan [9] published in 2013, 18 main targets are identified, including a $15 \%$ increase of resource productivity and a GDP creation of 1.8 trillion RMB from the waste recycling industry by the end of the 12 th FYP period. The action plan also defined nearly 80 specific indicators for developing $\mathrm{CE}$ in the whole society [9]. These include the 
material, energy and water consumption per unit output; utilization rate of waste; and reuse rate of industrial waters; etc.

Consumption is the keystone of the economic growth. Substantial consumer research has been done for analyzing and understanding the personal, environmental and behavioral factors of consumption [10]-[12]. Circular consumption (CC), as a new concept in $\mathrm{CE}$, has also attracted the increasing attention from academia, research and government, with a focus basically on $\mathrm{CC}$ theoretical or policy studies [1], [6], [13], [14]. However, for CC implementation in the real world, few current approaches have tackled the issue, such as circular consumption implementation models, mechanisms or measures. These are the focus of our study presented in this paper.

Circular consumption is an indispensible part of a circular economic system. It is also one of the driving mechanisms to achieve the CE development. However, at present there exist as yet no commonly accepted definitions of the concept. CC can be understood in different ways. We consider circular consumption as a new type of consumption that satisfies basic needs, improves the quality of life, and promotes the transition of consumers' social attitude and consumption behavior towards resource circularity and environment sustainability in order to achieve the goals of a circular economy based on the reduce-reuse-recycle principle.

Aiming at mitigating environmental degradation and resource depletion to sustain economic growth, circular consumption highly values the effect of " $3 \mathrm{R}$ " not only on reducing material/energy use and minimizing waste generation, reusing the used products, and recycling waste resources, but also on driving the change in consumption patterns and consumer lifestyles. From this perspective, CC can stimulate the economic growth in an environment-benign and resource-productive manner. At the same time, $\mathrm{CC}$ can also motivate the pro-3R lifestyles to harmonize the relationship between human and nature.

\section{A 3R IMPLEMENTATION FRAMEWORK FOR CIRCULAR} CONSUMPTION AND LIFESTYLE CHANGE IN COMMUNITY

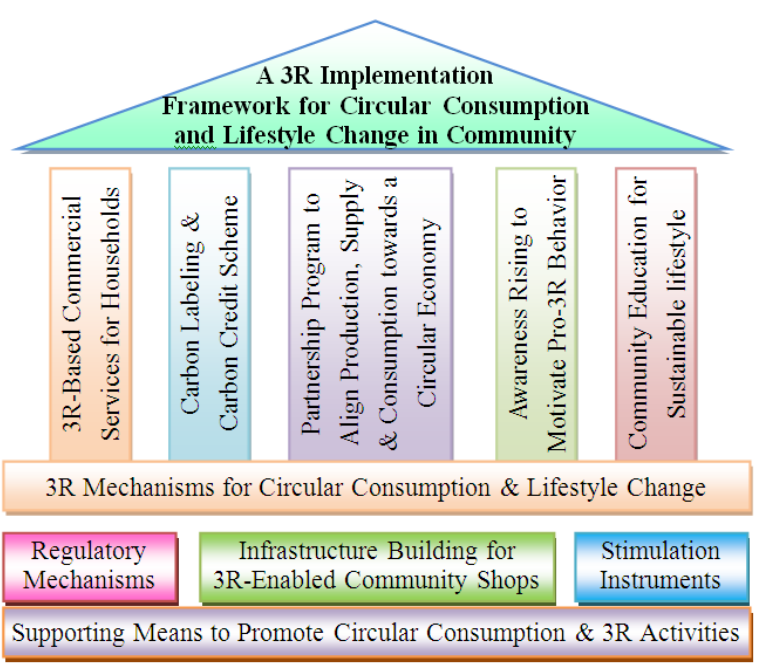

Fig. 2. A 3R implementation framework for circular consumption.

The 3R implementation framework is built on five key pillars (Fig. 2) for fostering a necessary transition towards circular consumption and alternative ways of green living in the community. Each of these pillars is explored in more depth in this section.

\section{A. 3R-Based Commercial Services}

As shown in Fig. 2, providing 3R-based commercial services is one of the $3 R$ mechanisms of the framework. What differentiate a $3 \mathrm{R}$-enabled community shop (3R-shop) from a conventional retailing store is that the $3 \mathrm{R}$-shop offers not only retailing services but also other commercial functions for residents to practice the $3 R$ concept. Such functions include low-carbon products sales, second-hand goods on-consignment and exchange, and household wastes collection and trading. The 3R-shops are based on community and serve the community to form the elemental cells of a low-carbon, circular consumption system in community. The purpose is for reducing, reusing and recycling household waste resources, as elaborated below.

Reduce: Through retailing of low-carbon and energy-efficient household goods, the 3R-shops support residents to reduce the energy and water consumptions and toxics/waste emissions at the use stage of household items. The 3R-shops also create a green consumption environment to enrich the pro-environmental shopping experience of residents and guide them towards a low-carbon lifestyle.

Up to $90 \%$ of the merchandises available in the $3 \mathrm{R}$-shops are low-carbon, energy-efficient or green products. Included are the energy-saving household electrical appliances (small types), water-saving kitchen supplies, solar series, green lighting and LED, biodegradable food wares, phosphor-free cleaning products, green stationery, etc. By bringing those products into homes, the 3R-shops embody the "reducing" concept of the $3 \mathrm{R}$ principle in residents' daily life.

Reuse: The 3R-shops provide the on-consignment and exchange services for residents to reuse their second-hand goods over multiple cycles. Through the resale and exchange services, the product useful life spans are extended, which benefits both the environment and economic growth. As we know, the economic and environmental values of second-hand items are considerably higher than the values of recycled materials. As such, the "reusing" function of 3R-shops brings higher economic and environmental values, compared to waste goods recycling, to both the buyer and seller. The significance of reusing the secondary is twofold: It helps those who prefer second-hand goods based on economic considerations and those who prefer the secondary because of their ecological philosophy or because the goods are considered "trendy" [15]. On the other hand, it provides an additional platform for residents to realize a ready money from their unused and idle items, which has actually allowed them to practice the $\mathrm{CC}$ concept for a rational use of resources.

Recycle: Functioning as a waste collection and transaction center, the 3R-shops facilitate residents to recycle their post-consumption goods. The "recycling" services meet the needs from residents for convenient and fair trading of the regenerative household waste. In China, most of the household discards are with economic values, if the items are accepted by waste collectors for recycling/recovery 
purposes. By providing a community norm of waste collection and sunshine trading, the 3R-shops promote transparent and fair buy-back and trade-in of used household goods, waste sorting at the source, waste online trading, regular sentinel site recycling, depot recycling, fixed or special collection day programs, etc. The collected waste items are then transferred to processing plants for materials recovery under the partnership program with the recycling industry (see Section III.C for details).

\section{B. Carbon Labeling and Carbon Credit Scheme}

The second pillar in the framework in Fig. 2 is the establishment of a carbon labeling and carbon credit scheme. As mentioned earlier, most of the products in the 3R-shops are low-carbon, green products. The common characteristics of the products include the following: built with lower embedded manufacturing and transport energy; made from non-toxic, environment-friendly, renewable, recycled or biodegradable materials; with relatively simple packaging; with higher energy-use or water-use efficiency at the consumption stage of the products; and other green features. Based on the identified green characteristics above and referenced to the environmental labeling standards (ISO 14020 series and PAS2050) and the best practices [16], a simplified carbon quantification, communication and rewarding method has been developed. Fig. 3 depicts the major action steps of the method. It has been used for estimating $\mathrm{CO} 2$ emissions of products and for stimulating sales of low-carbon goods in the 3R-shops.

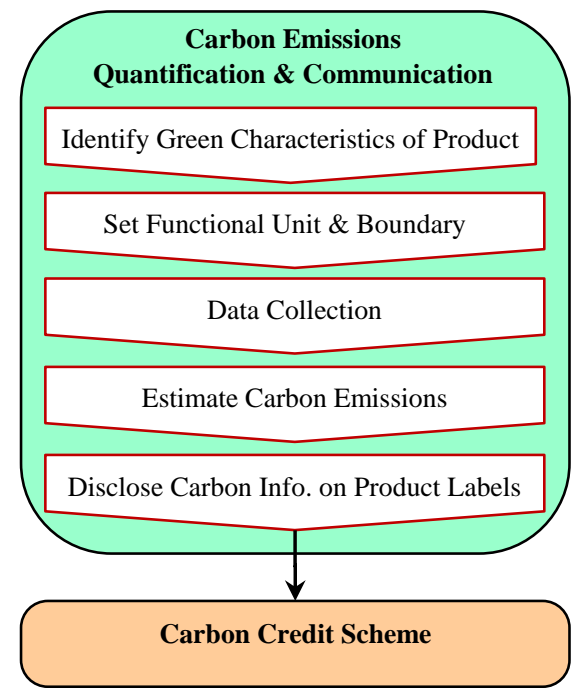

Fig. 3. A simplified carbon quantification, communication and rewarding method.

The derived $\mathrm{CO} 2$ information from the method in Fig. 3 is conveyed to customers by carbon labels on the products. A carbon disclosure label functions as a novel attribute on the consumer perceived value of low-carbon products. By providing additional information about the quantified carbon characteristics of a product, the label facilitates the comparison among products and guides consumers to make informed choices towards low-carbon commodity. In that sense, the carbon labels contribute to $\mathrm{CO} 2$ emissions reduction through more responsible consumption promoted by low-carbon products.

The carbon credit scheme in Fig. 3 is a stimulation mechanism to encourage community residents to practice $3 \mathrm{R}$ in their daily lives. The purpose is to reduce the environmental impact of consumptions and change residents' attitudes towards low-carbon products in the 3R-shops. Using an incentive card (details in Section III.F) and an electronic information platform, every $3 \mathrm{R}$ activity of a customer of the 3R-shop will be converted to certain $3 R$ credit points and accumulated on the incentive card. These $3 \mathrm{R}$ activities include: purchase of low-carbon products in the 3R-shops, use of the on-consignment or exchange services, trading of the used household items with the shops, etc. The accumulated points can be used for exchange of low-carbon products in the $3 \mathrm{R}$-shops.

\section{Partnership Program to Align Production, Supply and Consumption towards a CE}

Another mechanism of the $3 \mathrm{R}$ implementation framework in Fig. 2 is to set up a partnership program with manufacturers, waste processers, and distributors to align their actions for a common vision of circular economy. The implementation of the concept of CE needs the efforts from all these stakeholders to ensure the production, supply, use and disposal of household goods in a circular and sustainable way. For example, through low-carbon commodity sales, the 3-shops stimulate residents' consumption of low-carbon goods, while low-carbon consumption would drive production of low-carbon commodities, which in turn will encourage ever-increasing consumption of low-carbon goods. Similarly, through collection and trading of the post-consumption items, the 3R-shops promote waste resources recycling, while waste recycling would make more regenerated secondary materials available for production, which will increase the supply of low-carbon products to better meet residents' needs. Fig. 4 is the business model of the 3R-shops. It shows the interactions among the stakeholders of the 3R-shop, customer, supplier, producer and waste processer. Fig. 4 also indicates the contributions of each to the $3 \mathrm{R}$-based circular consumption system.

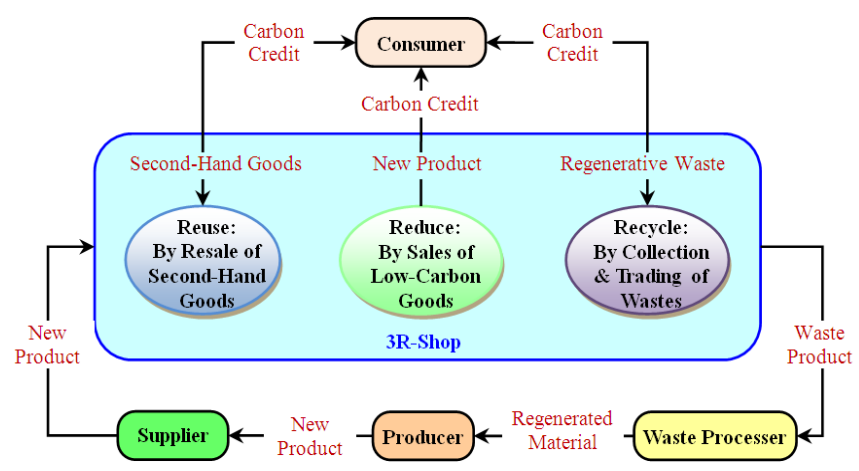

Fig. 4. Business model of the 3R-shops.

\section{Awareness Rising to Motivate Pro-3R Behavior}

Awareness rising is an important component of the framework in Fig. 2. Circular consumption and the $3 R$ principle are new concepts to many community residents, though most of them are aware of pollution and adverse environmental effects on the real life. However, yet there has been little evidence of behavioral change towards circular consumption and pro-3R activities in most communities. In 
general, residents' purchasing behavior has not become sensitive enough to the environmental characteristics of the products, rather the functional performances and prices of those products. Therefore, awareness rising would be an important task of the 3R-shops for motivating pro-3R behaviors and for advocating circular consumption.

Based on the real situation, the 3R-shops have organized various events and campaigns to raise the $3 \mathrm{R}$ awareness level of the public on how to achieve the targets of resource conservation, environment protection and circular economy through pro-3R behavior changes. These events include:

- Conducting information campaigns to promote energy efficient products, water conservation, waste emissions control, resources reuse and recycling, etc;

- Bringing low-carbon and green household goods to municipalities to allow residents' familiar with the goods and knowing their usage;

- Posting energy-saving, water-saving and green tips in the 3R-shops;

- Going to schools and organizations for promoting pro-3R behaviors and disseminating the benefits of behavioral change;

- Communicating 3R and circular consumption agendas to customers within the 3R-shops to develop their awareness about the impact of their consumptions;

- Distributing 3R brochures in the 3R-shops and other public sites; etc.

\section{E. Community Education for Sustainable Lifestyle}

Community education for sustainable lifestyle is another pillar of the 3R implementation framework in Fig. 2. Not like awareness rising in the last Section for individuals' behavioral change through promotions and campaigns, education for sustainable lifestyle will provide knowledge, information, values and skills to enable those who are with strong interest in $3 \mathrm{R}$ and $\mathrm{CC}$ to become drivers of lifestyle change towards a circular consumption society. Currently, there is a small portion of residents especially younger ones who are concerned about their lifestyles and the impact of lifestyles on the local environments. When they know the 3R-shops' functions, some approached to the shops looking for ideas and guidance on how to change and adapt their lifestyles towards more sustainable ones. This makes us to realize that information and education are essential in empowering residents and helping them to better understand not only the concepts of $3 \mathrm{R}$, circular consumption and $\mathrm{CE}$, but also the way how these concepts relate to their daily lives and to their consumption choices. Seminars and training sessions are organized for them with the government funding support. For these $3 \mathrm{R}$ and $\mathrm{CC}$ pioneers, they are expected to further identify their actions towards more sustainable lifestyles, as well as influence others around to develop alternate visions towards pro-3R and circular consumption lifestyles.

\section{F. Supporting Means to Promote Circular Consumption \& $3 R$ Activities in Community}

As shown in Fig. 2, the supporting means for $\mathrm{CC}$ and $3 \mathrm{R}$ with the framework include three components: the regulative, infrastructural and economic instruments.
Regulative instrument. Chinese government has adopted the $\mathrm{CE}$ and $3 \mathrm{R}$ approaches as new models to sustain its economic development and already passed legislation to support this strategy. There have been regulatory and institutional frameworks and sectoral policies available in China for promoting the development and implementation of $\mathrm{CE}$ and sustainable consumption [8], [9]. Governmental funding is also available to encourage business, consumers and organizations to practice $3 \mathrm{R}$ and $\mathrm{CC}$. The development and implementation of our 3R-shops is also received the fund support from the governmental bodies.

Infrastructural development. Facilities for retailing, consignment and exchange, and waste collection are required in order to provide residents with the $3 \mathrm{R}$ services. The 3R-shops are positioned to serve the residents in communities. As such, each shop is design with a business area about 200 square meters with a serving radius of two to three kilometers and covering five to six communities. Together, these 3R-shops have formed a multi-leveled commercial system for residents to practice $3 \mathrm{R}$ and CC. Fig. 5 is a photo of such a shop in Wuhan city, China.

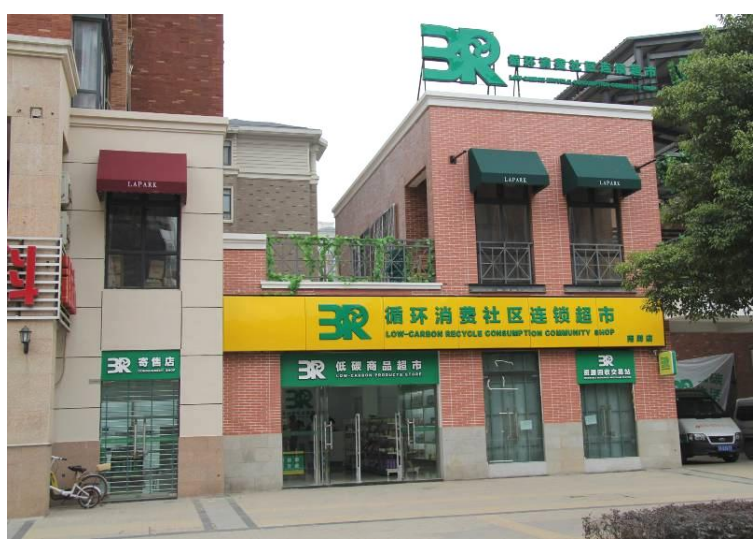

Fig. 5. The real scene of a 3R-shop in Wuhan, China.

Economic instrument. The economic instrument of the framework in Fig. 2 consists of an incentive card and a related electronic information platform. The card is designed for creating an incentive to increase the loyalty and demand for low-carbon and green household goods, thus to stimulate the supply and production of such products. Customers of the 3R-shops are issued with the card free of charge. With the cards, participants can accumulate credit points from purchasing low-carbon products, reusing the second-hand items, and recycling their regenerative waste as shown in Fig. 4. All credit points are managed by an electronic information system. Through the system, the carbon credits can be accumulated, verified and communicated to customers. The system together with the incentive card and product labels provides an open and transparent tool to make residents' carbon reduction effort quantifiable and visible. Participants in the scheme can redeem their carbon credits on the low-carbon and green products.

\section{CONCLUSION}

A 3R implementation framework has been developed for residents in communities to practice the concepts of circular consumption and promote the change of consumption 
patterns and lifestyles. By the end of 2012, the framework has been implemented in 20 3R-shops distributed in Wuhan and Jingment in China. The 3R-shops have fundamentally changed the traditional way of household products retailing, of the second-hand goods reusing, and of the household waste collection and recycling in the areas covered by the shops. Through the innovative business model, 3R services, and the advanced IT solutions, the 3R-shops linked the production, supply, consumption and disposal of household goods to form a circular consumption system to support $\mathrm{CE}$ and promote pro-3R lifestyles. A $3 \mathrm{R}$-shop is not only a convenient retailing store, but also a service center to raise the residents' awareness on resources and the environment, advocate green and circular consumptions, and encourage pro-3R lifestyles and behavioral change towards circular consumption. The 3R-shops have demonstrated the innovative functions that retailing shops can perform in encouraging $3 \mathrm{R}$ activities to achieve the goals of circular consumption.

Future research will be focused on the evaluation of how well these 3R-enabled shops are accepted, to what degree they have influenced the consumer activities and use behaviors towards circularity and sustainability, and how they can be replicated to achieve even broader implementations to support circular consumption practices and pro-3R lifestyle changes.

\section{REFERENCES}

[1] The Ellen MacArthur Foundation (EMF). Towards the Circular Economy Vol. 2: opportunities for the consumer goods sector. (2013), pp. 25-36. [Online]. Available: http://www.ellenmacarthurfoundation.org/news/new-report-towards-t he-circular-economy-vol-2.

[2] National Bureau of Statistics of China. BRICS Joint Statistical Publication 2013. [Online]. Chapter 3. pp. 17-26. Available: http://www.stats.gov.cn/tjsj/qtsj/jzgj2013/P020130329609360695522. pdf

[3] J. H. Pan, H. K. Wei, Y. C. Song, Q. Q. Shan, and Y. Q. Wang, Annual Report on Urban Development of China No. 6, Bejing, China: Social Sciences Academic Press, 2013.

[4] Institute for Global Environmental Strategies (IGES), IGES White Paper III: Sustainable Consumption and Production in the Asia-Pacific Region, Japan: Sato Printing Co. Ltd., 2010, Chapter 1, pp. 1-21.

[5] J. K. Staniškis, "Sustainable consumption and production: how to make it possible," Clean Technologies and Environmental Policy, vol. 14, no. 6, pp. 1015-1022, Dec. 2012.

[6] China Council for International Cooperation on Environment and Development (CCICED), CCICED Annual Policy Report: Economic Development Mode: Green Transformation, Bejing, China: China Environmental Science Press, 2012, Chapter 3, pp. 60-67.

[7] China Council for International Cooperation on Environment and Development (CCICED). Progress on environment and development (2011-2012). (2012). [Online]. Part I. pp. 8-21. Available:
http://www.cciced.net/encciced/event/AGM_1/2012agm/meetdoc/201 212/P020121206430995551789.pdf

[8] China, Circular Economy Promotion Law of China, Bejing, China: People's Publishing House, 2008, Chapter 1, Article 2.

[9] China, The Strategy and Short-Term Action Plan for the Development of Circular Economy, Bejing, China: People's Publishing House, 2013.

[10] M. Phipps, L. K. Ozanne, M. G. Luchs, S. Subrahmanyan, S. Kapitan, J. R. Catlin, R. Gau, R. W. Naylor, R. L. Rose, B. Simpson, and T. Weaver, "Understanding the inherent complexity of sustainable consumption: A social cognitive framework", Journal of Business Research, vol. 66, Issue 8, pp. 1227-1234, Aug. 2013.

[11] W. Kilbourne and J. Mittelstaedt, "From Profligacy to Sustainability: Can We Get There From Here?" in Transformative Consumer Research for Personal and Collective Well-Being, D. G. Mick, S. Pettigrew, C. Pechmann and J. L. Ozanne, Eds. New York: Taylor \& Francis, 2012, pp. 283-300.

[12] P. McDonagh, S. Dobscha, and A. Prothero, "Sustainable Consumption and Production: Challenges for Transformative Consumer Research", in Transformative Consumer Research for Personal and Collective Well-Being, D. G. Mick, S. Pettigrew, C. Pechmann, and J. L. Ozanne Eds. New York: Taylor \& Francis, 2012, pp. 267-281.

[13] China Council for International Cooperation on Environment and Development (CCICED), Energy, Environment and Development, Bejing, China: China Environmental Science Press, 2010, pp. 40-46.

[14] G. Y. Yan, "On circular consumption", M.S. thesis, Capital Normal University, Beijing, China, 2011.

[15] H. Arold and C. Koring. (2007). An investigation and analysis of the second-hand sector in Europe. [Online]. Available: http://www.qualiprosh.eu/download/European_Sector_Analysis_Rep ort_english.pdf

[16] Carbon Trust. (2008). Code of good practice on product GHG emissions and reduction claims. [Online]. Available: http://www.carbontrust.com/

Q. Z. Yang is a deputy director of the Circular Economy Research Center and a CE expert for the GEM High-Tech Co. Ltd in Wuhan, China. Dr Yang had been a senior research fellow with the SIMTech, Singapore. Her current research interest includes circular economy, 3R methodologies, circular consumption, sustainable waste management and urban mining.

Jifeng Zhou is a deputy general manager of the Shenzhen GEM High-Tech Co. Ltd and the CEO of the Wuhan GEM Co. Ltd in China. He has over 10 years of experience in resources recycling and reuse, powder materials analysis and quality management. He has been leading various research projects under the national 863 programs and the local science and technology development schemes focusing on solid waste recycling and materials recovery.

Kaihua Xu is the CEO of the Shenzhen GEM High-Tech Co. Ltd in China $\mathrm{Dr} \mathrm{Xu}$ has been working in the recycling industry in China for nearly 15 years and with rich experience in the development and commercialization of the waste recycling technologies. He has been awarded over 300 patents and developed over 70 industry standards in the areas of e-waste recycling, precious metals recovery from waste, methods and equipment for regeneration of extra-fine $\mathrm{Co}$ and $\mathrm{Ni}$ powders from industrial waste, etc. With his great contributions to the recycling industry in China, Dr Xu has received numerous national and provincial awards. Included are the National Science and Technology Progress Award, Invention Excellence Award, Resource Recycling Star of the Year, and so on. 